\title{
ORIGEN DEL TRATAMIENTO CONJUNTO DE LA NULIDAD RELATIVA Y LA RESCISIÓN EN EL TÍTULO XX DEL LIBRO IV DEL CÓDIGO CIVIL CHILENO
}

Nathalie Walker Silva*

\section{Resumen}

El objetivo de este trabajo es demostrar que el tratamiento conjunto de la rescisión y la nulidad relativa en el título xx del libro IV del Código Civil no obedece a un error atribuible a Andrés Bello. Al contrario, dicho tratamiento tiene una explicación histórica, que surge -de modo solapado y que, por lo mismo, ha pasado casi inadvertida- en el origen mismo de la regulación de la rescisión por lesión.

PALABRAS ClAVE: nulidad relativa, nulidad absoluta, rescisión.

AbSTRACT

The objective of this paper is to demonstrate that the joint treatment of the rescission and the relative nullity in the 20th title of 4th book of the chilean Civil Code is no way an accident or a mistake. On the contrary, that situation has an unnotice historical explanation in the origins of called laesio enormis.

KEY wORDS: relative nullity, Absolut nullity, rescission.

* Profesora de Derecho Civil, Facultad de Derecho, Universidad Andrés Bello. Dirección postal: Bellavista 0121, Providencia, Santiago de Chile. Correo electrónico: nathalie.walker@unab.cl. Artículo recibido el 12 de noviembre de 2018 y aceptado para su publicación el 28 de marzo de 2019. 


\section{INTRODUCCIÓN}

La normativa que regula la nulidad y la rescisión en nuestro Código Civil -situada, en líneas generales, en el título XX del libro $\mathrm{IV}^{1}-$, se inicia en el art. 1681, el cual dispone:

"Es nulo todo acto o contrato a que falta alguno de los requisitos que la ley prescribe para el valor del mismo acto o contrato, según su especie y la calidad o estado de las partes. (2) La nulidad puede ser absoluta o relativa".

Un primer aspecto interesante vinculado a la norma recién citada es la discusión que se ha generado en nuestra doctrina en torno al significado de la palabra 'valor' ahí contenida. Para los partidarios de la teoría de la inexistencia, 'valor' sería un sinónimo de 'validez' -no de existencia del acto- con lo que se afirma que un acto o negocio puede carecer de validez, pero seguir existiendo. Para aquellos que desconocen a la inexistencia como una categoría distinta de la nulidad, la palabra 'valor' denota una relación de conformidad o disconformidad del acto con las exigencias legales; de manera que, si el acto no cumple con los requisitos dispuestos por la ley para tener valor ante ella, será nulo por carecer de esa adecuación mínima requerida ${ }^{2}$.

El segundo aspecto de la norma que merece ser destacado, es que un acto puede ser nulo por dos causales genéricas: o le faltan requisitos exigidos por la ley en atención a su especie -caso en el cual será nulo, de nulidad absoluta- o el acto carece de requisitos prescritos por la ley en consideración a la calidad o estado de las partes. Nada más dispone la ley para aclarar esta críptica clasificación de la carencia de requisitos que le dan valor a los actos.

${ }^{1}$ En un reciente trabajo anterior nos dedicamos en extenso a demostrar que los supuestos rescisorios contenidos en el Código Civilson variados y sobrepasan con creces la fisonomía de la nulidad relativa, presente en el título Xx del libro IV. En efecto, en una reciente monografía de nuestra autoría hemos postulado y defendido la tesis de que existe una relación de género a especie entre la rescisión y la nulidad relativa. De modo que la nulidad relativa es solo uno de los varios casos o supuestos rescisorios regulados en el Código Civil chileno. En ese mismo trabajo, clasificamos dichos supuestos rescisorios en dos grandes grupos: 1. El supuesto rescisorio genérico, contenido en el título xx del libro IV y 2. Supuestos rescisorios especiales, que clasificamos en A) Aquellos basados en razones de equidad y justicia conmutativa; B) Aquellos fundados en la lesión a derechos de terceros y C) Aquellos supuestos rescisorios que he denominado "impropios" o "anómalos". WALKER (2019).

${ }^{2}$ Alessandri et al. (1998), tomo il, pp. 325-329; Vial del Río (2015), pp. 237-245. Un excelente estudio reciente sobre el punto se encuentra en SAN MARTíN (2015), pp. 745-784. 
Finalmente, el art. 1681 clasifica a la nulidad en absoluta y relativa, siguiendo las corrientes doctrinarias de la época de dictación del Código. De conformidad a lo dispuesto por este artículo, la nulidad relativa es:

"la sanción a todo acto o contrato a que falta alguno de los requisitos que la ley prescribe para el valor del mismo acto o contrato, según la calidad o estado de las partes"3.

Por su parte, el art. 1682, inc. $1^{\circ}$, explicita algunas de las causales de nulidad absoluta. Se refiere a la presencia de objeto o causa ilícita en el acto y a la nulidad producida por la ausencia de requisitos en consideración a la naturaleza de los actos. En efecto, la norma dispone:

"La nulidad producida por un objeto o causa ilícita, y la nulidad producida por la omisión de algún requisito o formalidad que las leyes prescriben para el valor de ciertos actos o contratos en consideración a la naturaleza de ellos, y no a la calidad o estado de las personas que los ejecutan o acuerdan, son nulidades absolutas. (2) Hay asimismo nulidad absoluta en los actos y contratos de personas absolutamente incapaces. (3) Cualquiera otra especie de vicio produce nulidad relativa, y da derecho a la rescisión del acto o contrato".

El inciso segundo complementa las causales de nulidad absoluta, disponiendo que esta clase de nulidad se encuentra presente, también, en los actos celebrados por personas absolutamente incapaces.

El inciso tercero y final del art. 1682, incorpora una frase de gran interés, al señalar -como se ha citado-: "cualquier otra especie de vicio produce nulidad relativa, y da derecho a la rescisión del acto o contrato".

La normativa recién aludida contiene, en su formulación, las claves para comprender las diferencias existentes entre tres instituciones con una fisonomía diferente -nulidad absoluta, nulidad relativa, rescisión-, pero que, al presentar elementos comunes -como ocurre con la igualación legal de sus efectos- tienden a ser confundidas. Esto último ocurre, principalmente, con los conceptos de nulidad relativa y rescisión.

En atención a lo anterior, este trabajo efectúa un tránsito desde las ideas de la doctrina clásica en la materia a los postulados de una doctrina más moderna, que otorga una nueva lectura en torno a las razones que llevaron a Andrés Bello a regular las nulidades y la rescisión de la forma en que lo hizo en el título xx del Código Civil. En atención a ello, revisare-

${ }^{3}$ Véase, por todos, Vial del Río (2015), p. 257. 
mos las normas de dicho título a la luz de los aportes doctrinarios que nos permitan interpretarla desde el foco de su utilidad y coherencia interna; no desde la búsqueda de errores.

\section{Aportes DE LA DOCTRINA CLÁSICA}

\section{EN TORNO A LA DISTINCIÓN ENTRE LAS NULIDADES Y LA RESCISIÓN}

La doctrina clásica en la materia se pronunció, en su momento, sobre la importancia de la distinción entre nulidad absoluta y relativa. Así, por ejemplo, Robustiano Vera -uno de los primeros comentaristas del Código Civil- reconocía que la división de la nulidad en absoluta y relativa, la tomó nuestro código de aquel de Napoleón. Añade, también, que la nulidad absoluta es equivalente a la antigua nulidad del derecho romano, y la relativa, a su rescisión ${ }^{4}$.

Para Robustiano Vera, la nulidad y rescisión no son lo mismo para el derecho, por más que, a veces, se confundan sus efectos. La rescisión invalida un contrato válidamente formado, por una justa causa descubierta con posterioridad a su celebración. La nulidad, en cambio, es una declaración de que el contrato no ha llegado a existir, por haber faltado en su formación alguno de los requisitos esenciales del mismo. Tanto la rescisión como la nulidad dejan sin efecto los contratos. La diferencia radica en que la rescisión los deja sin efecto por motivos de equidad -que no afectan realmente a su validez- y la nulidad, por su parte, los deja sin efecto por motivos que afectan a su misma existencia. Por lo mismo, las causas de rescisión y las causas de nulidad son y deben ser distintas ${ }^{5}$.

Para el autor en comento, las nulidades "perfectamente absolutas"6 son aquellas que provienen de actos de personas absolutamente incapaces. En la nulidad relativa, la ley, sin desconocer la existencia del contrato, desconoce sus efectos y, para Robustiano Vera, se llama relativa porque

${ }^{4}$ Vera (1896), p. 250.

${ }^{5}$ Ibid.

${ }^{6}$ En materia de nomenclaturas, las expresiones 'absoluta' y 'relativa', empleadas por el Código Civil han dado origen a diversas opiniones. Una de ellas es la de José María Manresa-que no es un autor chileno, pero estudió nuestro Código Civil. Este autor expresa que: "la nulidad, como su propio nombre lo indica, viene a declarar la ineficacia que ya el contrato lleva en sí; la rescisión produce, ocasiona directamente esa ineficacia que no era esencial; aquélla, por lo tanto, es absoluta en cierto modo, y ésta es más relativa". MANRESA y Navarro (1907), tomo ViII, p. 726. En el mismo sentido, Enrique Rossel opina que la denominada nulidad relativa opera cuando un acto o contrato es afectado por "vicios de menor entidad que le permiten subsistir, porque no afectan a sus condiciones vitales de existencia, pero que pueden producir su desaparecimiento, en un plazo más o menos breve", Rossel (1926), p. 125. 
se ha establecido en beneficio de ciertas personas ${ }^{7}$. La nulidad absoluta trata de resguardar el orden social; la relativa mira solo los intereses de los particulares ${ }^{8}$.

En consecuencia, cuando se está en presencia de una nulidad absoluta, el contrato no existe; mientras en la relativa sí existe. De modo que puede expresarse, con toda propiedad, que la nulidad es un modo de desconocer la obligación y sus efectos, en vez de establecer que es un modo de extinguir obligaciones, como la considera nuestro Código Civil .

En un sentido similar opinaba David Costa al señalar:

"la nulidad propiamente dicha, es la nulidad absoluta -lo que no existe-, llamada también radical para significar con ello que el acto o contrato estaba infectado ab initio, que jamás tuvo ni pudo tener vida legal. La nulidad imperfecta, o sea, la relativa, es, en cierto modo, menos que una nulidad, es una facultad otorgada a una persona para atacar un acto existente [...]: esta nulidad significa lo que es anulable, rescindible, las obligaciones susceptibles de anulación. Al servirse la ley de las palabras nulo, nulidad, casi siempre es a esta clase a la que se refiere; de suerte que las emplea con el significado de anulación, anulable" ${ }^{10}$.

José Clemente Fabres -influyente autor de este periodo-, considera que la palabra 'nulidad' sería impropia para expresar los vicios que se insertan en el marco de la denominada nulidad relativa. Para este autor, dicha nomenclatura solo es aceptable por la semejanza que adquiere por la absoluta, desde el minuto en que el acto o contrato perece por la rescisión judicialmente pronunciada, por cuanto se reponen las cosas al estado anterior y se otorga acción reivindicatoria contra terceros poseedores. Esta

${ }^{7}$ En la actualidad, Jorge Baraona postula que esta nulidad se llama "relativa" por el efecto obligatorio dispar que el acto produce: dado que la nulidad relativa se orienta a la tutela de ciertos intereses privados, solo tiene legitimación activa para demandarla la parte "en cuyo beneficio la han establecido las leyes o por sus herederos o cesionarios" (art. 1684 , inc. $\left.1^{\circ}\right)$. De tal modo que la relatividad de esta nulidad apunta al hecho de que solo algunos pueden valerse de ella, y otros no. Más aún, el acto relativamente nulo, respecto de la parte que no está protegida por la declaración de nulidad, produce sus efectos jurídicos normales, siéndole plenamente exigible y obligatorio. En cambio, respecto de la persona beneficiada por la nulidad, el acto debe entenderse como nulo. En síntesis, la nulidad es relativa porque "el acto sólo es nulo respecto de una de las partes y válido y obligatorio, para la otra”, BARAONA (2011), pp. 364 y 365.

${ }^{8}$ Vera (1896), p. 260. En cuanto a la naturaleza y requisitos del interés que debe ser demostrado al demandar la nulidad absoluta, consultar Domínguez (2008), pp. 541-559.

${ }^{9}$ Vera (1896), p. 260.

${ }^{10}$ Costa (1890), p. 290. 
nulidad es relativa en cuanto a sus efectos, porque pueden desaparecer si no se ejercita dentro de plazo la acción rescisoria; y también lo es en cuanto a las personas, porque no todas pueden invocarla, sino solo aquellas en cuya protección la ley la ha establecido ${ }^{11}$.

Para Fabres, el lugar oportuno del Código Civil para regular la nulidad relativa hubiese sido en los modos de extinguir las obligaciones, ya que la nulidad relativa produce la rescisión, cuya finalidad es poner término a los efectos del acto o contrato, aunque de distinta manera y con distintas consecuencias que los otros modos de extinción ${ }^{12}$.

Para este mismo autor, el acto o contrato rescindible es válido porque este debe respetarse y cumplirse mientras no se pronuncie judicialmente la rescisión, y también porque no puede rescindirse, sino lo que existe o vale, así como no puede sanearse lo que no existe o no vale ${ }^{13}$.

También considera que la nulidad relativa involucra la facultad temporal que concede la ley a determinadas personas para destruir los efectos del acto o del contrato; con lo que se declara implícita, pero en forma inequívoca, que el acto o el contrato produce efecto o que es válido ${ }^{14}$.

Precisamente, es Fabres quien inicia la tradición jurídica de considerar que la nulidad relativa "es una misma cosa que la rescisión"15. De ahí en adelante, de modo casi invariable, la doctrina nacional ha considerado a 14 la rescisión como un sinónimo de nulidad relativa ${ }^{16}$.

Este orden de ideas terminó de moldearse en la obra más completa e influyente que se ha escrito en Chile en materia de rescisión. En el libro: La nulidad y la rescisión en el Derecho chileno, Arturo Alessandri Besa ordena y complementa el pensamiento de Fabres en este punto, afirmando que

${ }^{11}$ Fabres (1908), tomo III, p. 137.

12 Op. cit., p. 163.

${ }^{13}$ Op. cit., p. 166. La idea de que lo nulo no puede rescindirse es antigua. Los primeros comentaristas del Código Civil la tomaron, entre otras fuentes, de Juan Heinecio, quien la expone y reitera en varias ocasiones en su obra. Por ejemplo, en materia de querella de inoficioso testamento, cuando señala: "Sin embargo, no siendo necesaria siempre esta queja, por el contrario, bastando a veces otros remedios, se pregunta: ¿̇en qué casos hace falta? Aquí observamos: 1) que no es necesario este remedio cuando son omitidos los hijos, o desheredados injustamente. Pues arriba vimos que semejante testamento era nulo ipso iure; y lo que es nulo no puede rescindirse. Por lo que mejor establecen los hijos en este caso la queja de nulidad, por la cual se destruye todo el testamento [...]". Heinecio (1835), tomo II, p. 475.

${ }^{14}$ Fabres (1908), tomo III, p. 170. En un sentido similar, Merino (1908), p. 26.

${ }^{15}$ FABres (1908), tomo III, p. 144. En igual sentido, afirmaba: "La nulidad que el Código francés ha colocado en la misma línea que la rescisión, como dice Delvincourt, es la nulidad relativa, no la absoluta o de pleno derecho".

${ }^{16}$ Véase, por todos, Alessandri (2008), tomo it, pp. 19-20; Vial del Río (2015), pp. $257-274$. 
el Código Civil trata como sinónimos los conceptos de nulidad relativa y rescisión. Asimismo, añade que, en ciertas oportunidades, el Código Civil incurre en imperfecciones del lenguaje ${ }^{17}$, que provocarían que el concepto 'rescisión' se utilice de manera impropia. De modo que, según el autor, existirían ocasiones en que el Código emplea la palabra 'rescisión' para referirse, más bien, a la resolución de ciertos negocios (como ocurriría en la reglamentación de la acción redhibitoria, art. 1857) ${ }^{18}$.

Solo desde hace unos cuantos años, ciertos autores se han animado a cuestionar este dogma de la igualación de la rescisión a la nulidad relativa. Esto se ha debido, principalmente, a que han desarrollado un estudio de la rescisión desde una perspectiva histórica, lo que les ha permitido superar los estrechos márgenes de actuación que posibilitaba la antigua exégesis de los textos legales ${ }^{19}$. Una muestra de este giro está conformada por la opinión de Jorge Baraona, que marca un quiebre profundo con el dogma descrito, en cuanto considera que Andrés Bello diferenciaba correctamente la rescisión de la nulidad relativa ${ }^{20}$. En tal sentido, este autor entiende que

${ }^{17}$ Las críticas de la doctrina al lenguaje técnico empleado por el Código Civil son muy antiguas. De ellas da cuenta un autor, en el año 1885 , al referirse a la sinonimia entre la nulidad relativa y la rescisión: "El Código ha corrido en esta parte la suerte de toda ley nueva que dispone materias que Códigos antiguos reglaban, que sin cambiar el fondo introduce modificaciones y reformas y que van a ser aplicadas y comentadas por personas empapadas en la legislación anterior y en la doctrina de ella, deducida, cuando aún no ha transcurrido bastante tiempo para que aplicaciones repetidas hayan ilustrado o sometido a estudio sus diversas disposiciones, y permitan abrazarlas en su conjunto y darse cuenta de los principios que en ellas dominan". Continúa indicando el mismo autor: "En estos casos, como cuando se corrigen pruebas de escritos propios en que más que el texto, se leen en recuerdos, los que estudian el Código lo leen bajo el prisma de lo que ya saben y recuerdan, o de doctrinas que se han habituado a tomar por guía y, sin advertirlo, prescinden del tenor del texto y lo interpretan y explican en conformidad a ellas. Bajo esa influencia, las mismas disposiciones que debían hacer notar el equivocado concepto en que se procede, se acomodan a los principios que se toman por guía, imputando al legislador faltas de que no es culpable, errores que no ha cometido. Esto explica que se atribuya a falta de método, a impropiedad del lenguaje, el que el Código extienda la palabra nulidad al vicio de que adolecen los contratos rescindibles", S.O (1885), pp. 213 y 214.

${ }^{18}$ Alessandri (2008), tomo iI, p. 19.

${ }^{19}$ En apoyo a la tesis de Jorge Baraona, puede señalarse que la diferenciación entre nulidad y rescisión no solo se infiere del art. 1682, sino del propio mensaje del Código, al referirse a la abolición de la restitutio in integrum respecto de los actos celebrados por menores: "Lo dispuesto sobre esta materia en el Código francés, en el de las Dos Sicilias, en el sardo y en otros, es mucho más conforme con la justicia y aún más favorable a los mismos pupilos. Según estos Códigos, el contrato celebrado por un menor sin el consentimiento de un guardador no es nulo ipso iure, aunque puede rescindirse".

${ }^{20}$ Muy pocos autores chilenos han desarrollado un estudio integral de la rescisión por lesión. Entre ellos se destaca, como pionero, Arturo Alessandri Besa (con su tratado: La nulidad y la rescisión en el Derecho Civil chileno, año 1949). Mucho tiempo después, 
la rescisión es el efecto propio de un acto que ha estado viciado, ya sea desde un punto de vista estructural o por defectos funcionales; en este último caso, causándose una lesión a una de las partes contratantes. Concibe la función rescisoria principalmente como protectora de un interés patrimonial y, por lo mismo, no la concibe como una sanción, sino como un remedio o una protección legal que busca restablecer un equilibrio patrimonial. Para este autor, en consecuencia, la rescisión encuentra una explicación distinta a la causa general de nulidad relativa ${ }^{21}$.

\section{UNA EXPLICACIÓN (MEDIATA) AL PROBLEMA \\ DE LA REGULACIÓN CONJUNTA DE LA RESCISIÓN Y LAS NULIDADES}

Resulta previsible que un primer acercamiento al enigma de la regulación conjunta de ambas instituciones induzca a postular que Andrés Bello siguió en esta materia el modelo francés, el cual, en el Código Napoleón, regula conjuntamente ambas clases de nulidades, en la sección: "De la acción de nulidad o rescisoria de los contratos". A su vez, podría añadirse que la distinción entre nulidad absoluta y relativa fue tomada por Andrés Bello de una clasificación análoga efectuada por Claude Étienne Delvincourt 16 y que se infiere del mismo $\operatorname{Code}^{22}$.

Sin embargo, tal explicación dista, por sí sola, de ser satisfactoria. En primer lugar, porque la asimilación entre nulidad y rescisión efectuada en el Code se explica por razones históricas y de índole procesal aplicables de manera específica al modelo francés, sin que se vinculen de manera directa con nuestra realidad jurídica. En segundo lugar, dicha regulación conjunta, más allá de consideraciones de tipo procedimental, obedece, más bien, a una razón de fondo, subyacente al origen remoto de la rescisión por lesión.

En efecto, en el derecho antiguo francés, la distinción entre nulidad y rescisión era importante, porque cuando una convención era nula, solo

encontramos a Loreto Mosquera Rojas (1998) y, ya en el siglo xxI, a Jorge Baraona González y Jaime Alcalde Silva. Ello no quiere decir que no haya habido preocupación por el tema, sino que el tratamiento efectuado por los otros autores fue, o en parte coincidente con las tesis desarrolladas por Arturo Alessandri Besa o, bien, solo trataron la rescisión a propósito del estudio de la nulidad relativa, la cual consideran una misma cosa que la rescisión.

${ }^{21}$ Baraona (2011), pp. 326-327.

${ }^{22}$ La distinción de Delvincourt es muy similar a la que Andrés Bello hace entre nulidad absoluta y relativa, por lo que es muy probable que la primera sea la base de la segunda. No debe perderse de vista, para efectos de este análisis, que el único autor citado por Andrés Bello en sus notas a los proyectos de Código Civil, en el título "De la nulidad y la rescisión” es Claude Delvincourt. Al respecto, véase Bello (1932), tomo v, p. 441. 
había que demandar u oponerse a la nulidad para obtener una declaración; mientras que, si la convención no era más que rescindible, había que conseguir cartas de rescisión, que el juez ratificaba si lo consideraba necesario. Esa necesidad de obtener cartas de rescisión se explica porque si el acto no era nulo, sino únicamente rescindible -gracias a que reunía las condiciones esenciales para la validez de los contratos-, el magistrado no podía por sí mismo rescindir ese contrato. Ese poder pertenecía solo al Rey. En consecuencia, la parte lesionada por el acto debía solicitar cartas de rescisión, las que eran emitidas por la Cancillería, previa solicitud que contenía la exposición de los hechos. Luego, el juez interino otorgaba las letras y rescindía el acto $^{23}$.

Con la dictación de la ley de 7 de septiembre de 1790, que suprime las cancillerías, el panorama descrito se modifica en forma radical. Al operar la eliminación de aquellas, los procedimientos para reclamar de la nulidad y la rescisión concluyen en uno solo. De ahí en adelante, se desarrollará una interesante discusión en torno a si continúan o no existiendo diferencias entre ambas formas de ineficacia de los actos ${ }^{24}$.

En consecuencia, para encontrar la explicación al aparente contrasentido de regular en forma conjunta las ineficacias estructurales de un acto (nulidad) con aquellas que solo lo hacen ineficaz desde un punto de vista funcional (rescisión), es preciso realizar un ejercicio comparativo con un pasado aún más remoto: ya no solo con aquel que conecta al Código Civil chileno y al francés, sino que es necesario examinar los vínculos existentes entre la normativa de nuestro Código y la regulación contenida en la famosa lex Secunda ${ }^{25}$.

\section{EL ANTECEDENTE REMOTO -Y GENUINO- DEL PROBLEMA DE LA REGULACIÓN CONJUNTA DE LA RESCISIÓN Y LA NULIDAD}

La aludida lex Secunda se encuentra contenida en el Código del Corpus Iuris de Justiniano y ha sido muchas veces postulada por la doctrina como antecedente remoto de la moderna rescisión por lesión ultra dimidium. $\mathrm{Al}$ respecto, si bien es cierto que la posibilidad de rescindir un contrato por lesión está incorporada en dos rescriptos atribuidos a los emperadores Diocleciano y Maximiano -tratados conjuntamente bajo el título de Leyes De rescindenda venditione-, es el primero de ellos (la lex Secunda) el

${ }^{23}$ Delvincourt (1813), tomo il, pp. 58-59.

${ }^{24}$ Duranton (1844), tomo XiI, pp. 591-592; Toullier (1824), tomo ViI, pp. 619-620.

${ }^{25}$ Accursio la refiere como: "ista est famosa lex". Véase CoRpus Iuris Civilis Cum GLOSSIS ACCURSII (2006), columna 1013. 
que tiene un contenido más determinante $\mathrm{y}$, por lo mismo, ha pasado a la historia como el hito inicial que moldea el principio sancionador de la rescisión por lesión enorme ${ }^{26}$.

Las Leyes De rescindenda venditione ["Sobre la rescisión de la venta"27] son rescriptos imperiales. Es decir, son respuestas dadas por el Emperador a un problema jurídico de un particular ${ }^{28}$. Es así como en la Ley Segunda aparece de manifiesto que Diocleciano y Maximiano dan respuesta a una consulta planteada por Aurelio Lupo. La Ley Octava, en cambio, va dirigida a Evodia. El primero de los rescriptos -Ley Segunda- sería del año 285 d.C. La Ley Octava, dataría del año 293 d.C.

El texto de la Ley Segunda, cuyo conocimiento ha llegado hasta nosotros mediante el Corpus Iuris Civilis, es el siguiente: C. 4. 44, 2:

"Si tú o tu padre hubiereis vendido a un precio menor una cosa de mayor precio, es humano que, o restituyendo tú el precio a los compradores, recobres el fundo mediante la autoridad del juez; o bien, si el comprador lo prefiere, recibas tú lo que falta para el precio justo. Parece ser precio menor, si no se ha pagado ni la mitad del precio verdadero" 29 .

${ }^{26}$ Walker (2017), p. 133; Walker (2019), p. 37.

${ }^{27}$ En forma tradicional, la doctrina ha asimilado el verbo rescindere al concepto de nulidad, Piccirillo (1971), tomo Xv, p. 574; Tuzov (2009), p. 156. Ello, sobre la base de la distinción entre las leyes perfectae, minus quam perfectae e imperfectae, contenida en el Epítome de Ulpiano, GuZmán (1996), tomo I, p. 29; Di PAOla (1966), pp. 39-67; MASI (1978), p. 860. Según esa clasificación, las denominadas leges perfectae-que son las que aquí nos interesan- sancionarían con la nulidad a los actos prohibidos. Precisamente, como en el Epítome se alude a que las leges perfectae "rescinden" el acto, se ha tomado el verbo 'rescindir' como sinónimo de 'anular'. Pero este planteamiento pierde sustento cuando se demuestra que la rescisión no era un concepto que tuviera un marcado sentido técnico, que era extraño al pensamiento jurídico clásico, PiCCIRILlo (1971), tomo Xv, p. 575 y que ni siquiera la jurisprudencia podía entregar un concepto dogmático refinado de nulidad. En consecuencia, no se podía pedir a los juristas romanos que nos entregaran un concepto uniforme o técnico de la rescisión, porque simplemente no existía, WALKER (2019), p. 24.

${ }^{28}$ Burke (1830), pp. 223-224; Bueno (2013), p. 382; Walker (2017), p. 133. Según Fabrizio Ciapparoni: "Para la doctrina jurídica intermedia, el rescripto es una fuente normativa, a veces de un alcance muy particular, expresión de la voluntad soberana directa a la solución de un caso concreto". Ciapparoni (1968), tomo xv, p. 587.

${ }^{29}$ Traducción de García (1962) p. 12. Texto original: C. 4. 44, 2: Impp. Diocletianus et Maximianus AA. Lupo: "Rem majoris pretii si tu vel pater tuus minoris distraxerit, humanum est, ut vel pretium te restituente emptoribus fundum venundatum recipias, auctoritate judicis intercedente: vel, si emptor elegerit quod deest iusto pretio recipias. Minus autem pretium esse videtur, si nec dimidia pars [veri] pretii soluta sit”. CORPUS IURIS Civilis CUM Glossis ACCURSII (2006), columnas 1014 y 1015. 
Por su parte, el texto de la Ley Octava es: $C .4,44,8$ :

"Si tu hijo -con tu consentimiento- ha vendido tu fundo, para obtener la nulidad de la venta deberás justificar el dolo resultante de los artificios y acechanzas del adquirente, o la amenaza de tormentos corporales, y aun de muerte, que empleó para obligarle a celebrar el contrato. Por cuanto el solo motivo de que alegaras que el fundo no se vendió por su justo valor, no bastaría para hacer rescindir la venta. En efecto, si atiendes a la naturaleza del contrato de venta; si consideras que el comprador trata de comprar al menor precio posible, y que el vendedor desea obtener la mayor ganancia posible, y que no llegan a entenderse ni a ajustar su contrato sino después de muchas discusiones; el vendedor disminuyendo poco a poco el primitivo precio, y el comprador, por su parte, añadiendo algo a lo primeramente ofrecido, y que al fin convienen en un precio; comprenderás, entonces, que ni la buena fe -que es la esencia del contrato de venta-, ni ninguna otra razón permite que se te conceda por este solo motivo la rescisión de un contrato terminado por consentimiento mutuo. A menos que se te hubiese dado un precio menor a la mitad del valor del fundo cuando tuvo lugar la venta, debiéndose en tal caso conceder al comprador la elección arriba ofrecida" ${ }^{30}$.

De la breve formulación de la lex Secunda pueden extraerse algunos principios con los cuales ha trabajado la doctrina desde esa época hasta hoy, y que subsisten, por cierto, en el esquema interno de nuestro Código Civil. El primero, nos indica que es posible dejar sin efecto la venta de una cosa $(\mathrm{rem}) \mathrm{y}$, específicamente un inmueble (fundus) cuando ha sido vendido a un precio inferior al justo. El segundo principio, hace énfasis en el fundamento equitativo de la institución (humanum est) y que opera solo mediante una sentencia judicial (auctoritate iudicis). El tercero, incorpora

${ }^{30}$ Traducción libre, sobre la base de la efectuada por Merello (1989), p. 117. Texto original: C.4.44, 8: Impp. Diocletianus et Maximianus AA. et CC. Aureliae Euodiae: "Si voluntate tua fundum tuum filius tuus venumdedit: dolus et calliditate atque insidiis emptoris argui debet, vel metus mortis, vel cruciatus corporis imminens detegui, ne habeatur rata venditio. Hoc enim solum, quod paulo minori pretio fundum venditum significans, ad rescindendam venditionem invalidum est. Quod si videlicet contractus emtionis atque venditionis cogitasses substantiam, et quod emptor viliore comparandi, venditor cariori distrahendi votum gerentes, ad hunc contractum accedant, vixque post multas contentiones, paulatim venditore de eo quod petierat detrahente, emptore autem huic quod obtulerat, addente, ad certum consentiant pretium: profecto perspiceres, neque bonam fidem, quae emptionis atque venditionis conventionem tuetur, pati neque ullam rationem concedere, rescindi propter hoc consensu finitum contractum, vel statim, vel post pretii quantitatis disceptationem; nisi minus dimidia iusti pretii, quod fuerat tempore venditionis, datum est, electione iam emptori praestita servanda”. Véase Corpus IURIS Civilis Cum GLOSSIS ACCursir (2006), columnas 1017 y 1018. 
la posibilidad de mantener vigente el contrato si el comprador satisface el suplemento del precio (iusto pretio). Y el cuarto principio dispone que el remedio solo se hará aplicable cuando el precio pagado por el comprador sea inferior a la mitad del valor de la cosa vendida (minus autem pretium esse videtur, si nec dimidia par veri pretii soluta sit $)^{31}$.

El caso planteado en la Ley Octava, puede resumirse en estos términos: el hijo de Evodia vendió un fundo -con la autorización de este último- por un precio algo menor al justo precio y lo que se pretende es rescindir el contrato. Al problema expuesto, los emperadores responden de manera clara: para rescindir la venta no basta haber vendido a un precio "paulo minore" -poco menor-; es preciso, además, haber sufrido dolo o miedo. En esta exigencia, se aparta de la Ley Segunda, la que no requiere un elemento subjetivo para la rescisión, pero sí se asemeja a ella en cuanto establece un límite al desequilibrio en las prestaciones en su parte final, en la frase: "a no ser que se te hubiese dado un precio menor a la mitad del valor del fundo cuando tuvo lugar la venta" ${ }^{32}$.

La relevancia de los principios contenidos en las Leyes De rescindenda venditione-y especialmente, los de la lex Secunda- es enorme para el tema en estudio. Su influencia es tan grande que no existe ningún Código Civil, desde el francés a la actualidad, que no utilice los criterios allí presentes 20 para elaborar soluciones propias al problema del desequilibrio contractual. El Código Civil chileno, desde luego no escapa a esa realidad y, por lo mismo, es posible reconocer en la normativa sobre rescisión que aquel efectúa, el mismo afán de tutela del contenido del contrato que animaba al remedio rescisorio configurado inicialmente en el siglo III d.C. y refundido un par de siglos más tarde en el Corpus Iuris Civilis.

\section{El CONTROL DE LA BUENA FE EN LAS LEYES DE RESCINDENDA VENDITIONE} Y SU PROYECCIÓN EN EL ART. 1681 DEL CódIGo CIVIL

Una premisa fundamental y que permite cambiar el enfoque del problema de la regulación conjunta de la nulidad y la rescisión en el título xx del libro IV del Código Civil chileno es que el mencionado título De rescindenda venditione contiene una regulación conjunta tanto del comportamiento que deben observar las partes contratantes como del contenido del negocio. En esa regulación, el elemento unificador y que otorga sentido a elementos que parecen más bien diferentes entre sí, es la buena $\mathrm{fe}^{33}$.

${ }^{31}$ Alberruche (2010), p. 37.

${ }^{32}$ Walker (2019), p. 39.

${ }^{33}$ Sciuto (2000), p. 428; Ziliotto (2007), p. 627. En Chile, Patricia López se muestra contraria a considerar a la buena fe como fundamento del instituto de la rescisión por lesión. 
Tal como ha señalado la académica Paola Ziliotto, en el título De rescindenda venditione, la buena fe aparece como un "criterio de juicio unitario", en torno al cual se deben valorar dos momentos diversos de la actividad negocial. Estos dos aspectos o momentos son:

1. El comportamiento de los contratantes y

2. El contenido del negocio ${ }^{34}$.

En consecuencia, para Paola Ziliotto, es preciso diferenciar si el juicio de buena fe tiene por finalidad valorar el comportamiento de las partes o la reglamentación de intereses (o contenido del negocio) ${ }^{35}$.

En primer lugar, si la buena fe persigue examinar cómo las partes se han conducido en la celebración del contrato (su comportamiento), se atenderá a la calidad de estas ${ }^{36}$-esto es, precisamente, lo que hace el art. 1681 del Código Civil, empleando idéntica terminología: "calidad o estado de las partes"-. Lo anterior explica por qué la Ley Octava hace directa alusión al dolo y a las amenazas: en ese ámbito, las exigencias de la buena fe se orientan a valorar el comportamiento que han tenido los contratantes en la celebración del negocio. Así, será contrario a la buena fe ese comportamiento incorrecto y el contrato podrá ser invalidado por las causales de violencia o de dolo ${ }^{37}$.

En un segundo momento, la buena fe servirá para valorar el contenido del contrato ${ }^{38}$. En tal caso, si el juicio de buena fe tiene por objetivo solo la reglamentación de intereses, se considerará exclusivamente la medida del intercambio. En consecuencia, será contrario a la buena fe

Según, la autora ello "resulta vago e impreciso, toda vez que su progresiva expansión y utilización por la doctrina la ha convertido en una 'cláusula general' o norma abierta, cuyo contenido abstracto sólo adquiere una significación concreta en cada una de las figuras en que el deber de lealtad, rectitud y corrección que ella evoca se manifiesta”. LóPEz DíAz (2015), p. 117. No concordamos con esta opinión, principalmente por dos razones. Primero, discordamos desde un punto de vista histórico, puesto que la rescisión nace de la mano de los contratos de buena fe. Es en el contrato de compraventa donde se produce la primera aplicación conocida del instituto y eso no puede ser solo una coincidencia. Segundo, porque la amplitud del principio de la buena fe es lo que permite dar un contenido -no vago, sino muy concreto- a un gran número de situaciones asociadas al comportamiento de las partes y al contenido del contrato. Por lo mismo, es frecuente que se invoque el art. 1546 del C.C. para efectos de integrar el contenido de las obligaciones que las partes asumen y que no siempre pactan de modo íntegro o manifiesto. WALKER (2019), p. 357.

${ }^{34}$ ZiliotTo (2007), p. 627.

${ }^{35} \mathrm{Ibid}$.

${ }^{36}$ Ibid.

${ }^{37}$ Así, elementos como el dolo, la fuerza y, bajo la óptica compilatoria, la lesión ultra dimidium, constituyen una violación del principio de la buena fe, Sciuto (2000), pp. 428 y 429.

${ }^{38} \mathrm{El}$ contrato es protegido por el derecho no solo porque es un acuerdo de voluntades, sino que, también -y principalmente-, porque se parte del supuesto de que contiene una regulación de intereses equitativa para las partes. WALKer (2017a), p. 711. 
"el acuerdo que contenga un desequilibrio inaceptable entre las prestaciones, superior a los límites inherentes a la realidad de la contratación y a la estructura del mercado"39.

Aquello permite explicar por qué el art. 1682 del C.C. -norma cuyo ámbito de aplicación excede los límites de la mera nulidad-, incorpora una mención expresa a la rescisión del acto o contrato (en su inciso final). En tal sentido, el espíritu que está detrás de la sanción al acto lesivo -desde la lex Secunda en adelante, incluido, por cierto, nuestro Código Civil- es la consideración de que las exigencias de la buena fe en la vida negocial no se satisfacen solo con la sanción a los hoy denominados vicios del consentimiento ${ }^{40}$-ámbito que el Código deja entregado a la nulidad relativa-, sino que también alcanzan a la valoración del acto o contrato, considerado como un resultado. Resultado en el que, necesariamente, debe estar presente la equidad.

En tal sentido, postulamos que, cuando los artículos 1681 y 1682 emplean el término 'valor' -aplicado a los actos o contratos- dicha valoración está vinculada no solo a la verificación de la existencia o validez del negocio ${ }^{41}$, sino, también -y más bien-, al control de la buena fe. Esta última constituye el criterio o medida con que se valora al acto o contrato para determinar si será necesario aplicar la rescisión (mirado el contenido del negocio) o la nulidad relativa (mirado el comportamiento de las partes), en caso de que tal valoración arroje un resultado contrario a los dictados de la buena fe.

En cuanto al contenido del título xx del libro IV, más que en presencia de una categoría dogmática de las voluntades contractuales viciadas,

${ }^{39}$ ZiLiotтo (2007), p. 627. Esta idea ya estaba presente en Juan Heinecio, fuente importante en los trabajos de Andrés Bello. Sobre este tópico, señala este autor: "Por lo relativo al precio, como éste deber ser justo, se sigue que también pueda rescindirse la venta por la lesión enorme o en más de la mitad de aquel [...] porque tal perjuicio no es conforme con la buena fe". Heinecio (1834), tomo i, p. 314. En tal sentido, el principio jurídico de la buena fe -que a la vez sustenta a la lesión contractual- permite rastrear de manera directa la justicia contractual y valorar en concreto los contratos efectivamente celebrados en el tráfico jurídico, Gómez (2008), p. 1641.

${ }^{40}$ La categoría dogmática de "vicios de la voluntad" o "vicios del consentimiento" surge en el seno de las escuelas racionalistas de los siglos XVI y XVII, "a partir de una casuística que fue formándose lenta y progresivamente. Esta progresión atravesó por las siguientes fases: en un primer momento se admite que se impugnen los contratos arrancados por la violencia o en que uno de los contratantes ha prestado el consentimiento porque ha obrado impulsado por el miedo; en un segundo momento, se admite la impugnación de aquellos contratos en que uno de los contratantes ha resultado engañado (dolo in contrahendo). Sólo muy tardíamente se discute la influencia del error sufrido por uno de los contratantes". Díez-Picazo (2007), tomo I, p. 186.

${ }^{41}$ Para una síntesis de la doctrina clásica en la materia, véase Alessandri et al. (1998), tomo II, pp. 325-329. 
nos encontramos en presencia de una serie de supuestos en los cuales se decide acerca de la justicia o la injusticia de la vinculación contractual. En tal sentido, la decisión no recae tanto sobre si el consentimiento se encontraba o no viciado, sino, más bien, si es justo o injusto que ese contratante quede o no vinculado por el acuerdo y continúe o no estándolo. Para esos efectos, será necesario enjuiciar su propia diligencia y valorar si la situación de la otra parte contratante es digna de ser protegida ${ }^{42}$.

$\mathrm{Si}$-como ha considerado la doctrina tradicional- la valoración que efectúan las normas mencionadas, se restringe solo a examinar la existencia o validez del negocio, la rescisión no tiene ahí ninguna cabida. Y es precisamente por este razonamiento restringido que se ha sugerido que la rescisión es sinónimo de nulidad relativa. En un esquema de pensamiento como ese -que solo admite la existencia de nulidades en el título xx del libro IV- carece de sentido incorporar la rescisión, instituto que, desde sus más remotos orígenes conocidos, ha permitido privar de efectos a ciertos actos válidamente celebrados.

\section{VÍNCULO EXISTENTE ENTRE LA RESCISIÓN Y LA NULIDAD en el título XX del Código CiVIL}

En el esquema interno del Código Civil, la nulidad relativa se encuentra emparentada con la rescisión no solo por sus efectos (art. 1687) ${ }^{43}$, sino, también, porque ambas comparten un mismo fundamento, conformado por la tutela de la buena fe en la contratación. Más aún, la nulidad relativa configura un caso particular de rescisión: uno más de tantos otros que se regulan en diversas materias. Existe, por tanto, una relación de género a especie entre los conceptos de rescisión y nulidad relativa, siendo la rescisión el género ${ }^{44}$.

Por consiguiente, puede concluirse que la cercanía que presenta la nulidad relativa con la rescisión es mayor que la que tiene con la nulidad absoluta, con la que solo comparte la igualación de los efectos.

Del examen de la evolución histórica experimentada por la rescisión y la nulidad, puede concluirse que la denominada "nulidad absoluta" siempre ha estado vinculada a una valoración acerca de la existencia misma del negocio. Así, si el negocio cumple con los requisitos conside-

${ }^{42}$ Díez-Picazo (2007), tomo I, p. 186.

${ }^{43}$ Para Jaime AlCalde, la nulidad relativa y la rescisión "pertenecen a una misma categoría (género próximo), por la igualación de sus efectos que hace el Código Civil”. Alcalde (2010), p. 74.

${ }^{44}$ Walker (2019), p. 244. 
rados por el derecho para su formación, nacerá y producirá sus efectos con normalidad (art. 1444 del Código Civil). En cambio, si no contiene esos requisitos mínimos, o se considerará como si nunca hubiese existido -se le desconocerá y se le despojará de consecuencias sin más, como ocurría en Roma $-{ }^{45}$, o se le privará de efectos por sentencia judicial (como opinaba, bajo ciertos supuestos, la doctrina tradicional de raigambre francesa).

La nulidad relativa, en cambio, ha estado generalmente asociada a la privación de efectos a un acto válido, mediante una sentencia judicial. El origen remoto de la nulidad relativa se encuentra en el instituto romano de la restitutio in integrum, que permitía al pretor retrotraer los efectos de un acto ya celebrado -y perfectamente válido en cuanto a su estructura-, debido a que tales efectos resultaban perjudiciales para ciertas personas, en atención a su estado o "calidad". Esta restitutio in integrum incorporaba, entre otras, las causales de dolo, fuerza y error, al igual que hoy acontece con nuestra nulidad relativa del título xx del libro IV. De tal manera que, desde su concepción original, este tipo de "nulidad" ha comportado la privación de efectos a un acto válido, por atentar contra la buena $\mathrm{fe}^{46}$.

La situación descrita se mantiene inalterable hasta el trabajo de la doctrina anterior a la codificación ${ }^{47}$, la que traspasa su legado al Código Civil francés. En efecto, este introduce una alteración profunda en la 24 forma de concebir la teoría de las nulidades, al tratar como sinónimos la nulidad y la rescisión. Dicho cambio provoca una gran confusión en la

${ }^{45}$ En un primer momento, los romanos clasificaron el contrato en cuanto a su utilidad para producir efectos, distinguiendo entre contrato utile: aquel que, válido o no, producía sus efectos e inutile: aquel que estaba en condiciones de producir efectos, pero no lo hacía. Solo en una época más tardía, idearon la categoría de la nulidad, aplicada a actos que jurídicamente no existían (nullum). Piccirillo (1968), tomo Xv, pp. 575; Martín (1995), p. 82; WALKer (2019), pp. 24-25.

${ }^{46}$ Nótese también, en este punto, que ninguna de las causales que autorizaban la restitutio era más importante que la otra: todas se situaban a un mismo nivel y cada una se analizaba en su ámbito propio, no en comparación con las demás. Véase, por todos, GuZMÁn (1996), tomo I, pp. 201-206.

${ }^{47}$ Ya en Robert PотнIER encontramos las primeras ambigüedades destacables en cuanto a la diferenciación entre nulidad y rescisión. En efecto, este autor contrapone la nulidad y la rescisión, señalando que la primera actúa de pleno derecho y la segunda, a petición de parte. Dice: "la falta de una de las cosas que son de la esencia del contrato impide que exista clase alguna de contrato; algunas veces esa falta cambia la naturaleza del contrato". Pothier (1821), tomo i, p. 82. En cambio, en caso de existir fuerza o dolo, el contrato existe, pero los afectados "pueden hacerlo anular y rescindir, obteniendo al efecto cartas de rescisión", op. cit., p. 96. Hasta ahí no hay problema. Este se produce, en el esquema de este autor, cuando expresa que el acto es también nulo "cuando la causal por la cual el compromiso ha sido contratado es una causa que hiere la justicia, la buena fe, o las buenas costumbres" op. cit., p. 108. Con esta última declaración, sitúa a la causa ilícita y a los actos atentatorios contra la buena fe dentro de las causales de nulidad y no de rescisión. 
doctrina, la que se traslada -por cierto- a los códigos que se inspiraron en el modelo francés.

Si bien nuestro Código Civil trata a la nulidad relativa como si fuese una verdadera nulidad -al llamarla "nulidad" consigue acercarla, al menos en apariencia, a la nulidad absoluta-, esto no consigue despojarla de su naturaleza rescisoria. Como ya se ha enunciado, la nulidad relativa es una especie de rescisión, porque está vinculada en forma estrecha a la equidad, a la buena fe y al perjuicio patrimonial -todos estos, elementos que históricamente han estado presentes en la configuración del remedio rescisorio-. Respecto del elemento del perjuicio, hemos de detenernos un momento para efectuar ciertas reflexiones necesarias para profundizar en el vínculo entre nulidad relativa y rescisión.

\section{El CONCEPTO DE ‘VICIO’ EN EL TítULO XX DEL LIBRO IV}

El concepto de 'vicio' al que aluden los artículos 1681 y 1682 de nuestro Código Civil se asocia, dentro del mismo cuerpo legal, no solo a las causales propias de las nulidades (absoluta y relativa), sino que se extiende, también, a otras causales de rescisión que aquel contempla. Es por eso que, por ejemplo, utiliza la denominación de "vicios redhibitorios" y, producto de esta nomenclatura, parte de la doctrina considera que aquellos producen nulidad relativa. En efecto, hay un vicio y esta palabra es asociada, indefectiblemente, a la nulidad de un negocio. Pero eso, en rigor, no acontece en la materia aludida, gracias a que el Código Civil ha dotado de una acción de carácter rescisorio al comprador afectado.

Es posible afirmar, entonces, que en los artículos 1681 y 1682, los denominados "vicios" no resultan ser solo del consentimiento, sino que podríamos llamarles, de modo más genérico: "vicios atentatorios contra la buena fe" ${ }^{48}$; dentro de los cuales se sitúa el error, la fuerza y el dolo, y a los que se añade, también, la lesión. Esta última no constituye un vicio del consentimiento ${ }^{49}$ en el esquema del Código Civil, pero sigue estando presente en la normativa del título XX del libro IV como un remedio aplicable en el supuesto de que el contenido del contrato atente contra los dictados de la buena fe.

${ }^{48}$ Walker (2019), p. 246. Por ejemplo, para Iñigo de la Maza, el error y el dolo no están orientados exactamente a la protección del consentimiento, sino que son, más bien, mecanismos de distribución del riesgo de la información defectuosa durante la negociación del contrato. De la MAZA (2011), pp. 116-117.

${ }^{49}$ La lesión fue considerada por Andrés Bello en algún momento -en los Proyectos de Código- como uno más de los vicios del consentimiento, sistematización que, en definitiva, no prosperó, BELlo (1981), tomo Xv, p. 390. 
Debido a lo anterior, la frase del art. 1682, inc. final: "cualquiera otra especie de vicio produce nulidad relativa, y da derecho a la rescisión del acto o contrato", puede ser entendida, además, como un mandato de aplicación de las normas que rigen la nulidad relativa a todos los casos en que el Código efectúe una referencia a determinados "vicios", aunque técnicamente no se trate de casos de nulidad relativa, sino de rescisión.

Visto el problema desde este último punto de vista, no resulta extraño que el Código Civil contemple en forma expresa a la rescisión en el mismo lugar en que trata la nulidad relativa. En su esquema, ambos institutos persiguen el mismo objetivo: resguardar la presencia de la buena fe, tanto en el aspecto vinculado al comportamiento de las partes como al relacionado con el contenido del negocio. Es más, consideramos que la finalidad última de la valoración que hace la ley -basada en la buena fe-es resguardar el contenido del contrato. Finalidad que se puede lograr de un modo directo (a través del remedio rescisorio) o de una forma indirecta, por medio de la nulidad relativa del acto que contenga vicios del consentimiento.

Dentro de este nuevo enfoque, los vicios del consentimiento pueden ser estimados como mecanismos que permiten controlar el resultado final del negocio convenido. Así, la sanción del error, la fuerza o el dolo no hace más que anticiparse a un determinado resultado: el resultado $26 \operatorname{lesivo}^{50}$. De modo que un negocio celebrado en tales condiciones hace presumible que, desde un punto de vista patrimonial, se produzca una ventaja intolerable para una de las partes, en desmedro de la otra. Por ende, la diferencia cualitativa entre un vicio del consentimiento y la lesión es que, en los primeros, el perjuicio patrimonial se presume ${ }^{51}$-por haber

${ }^{50} \mathrm{Al}$ respecto, se ha expresado: “cuando hay error de una o de las dos partes, no puede ser óptimo el intercambio o asignación de bienes que se realiza en virtud del contrato [...]. Esta circunstancia conduce casi necesariamente a una lesión económica [...] que acaba siendo un presupuesto decisivo para la prosperabilidad de la impugnación". CARRASCO (2010), p. 274. En un sentido similar, Antonio Manuel Morales Moreno ha expresado: "El contrato anulable (defectuosamente querido) es, en muchas ocasiones (error, dolo, provecho excesivo), además (y quizás fundamentalmente), un contrato económicamente dañoso en sí mismo, para el contratante que padece el vicio”, Morales (2011), p. 409.

${ }^{51}$ Así lo ha manifestado también Antonio Manuel Morales Moreno, a propósito del Código Civil español. Para el autor, en el caso de los vicios del consentimiento, la anulación del contrato es "un remedio de efecto sanatorio o indemnizatorio (restitutio in integrum), que ofrece la ventaja de no tener que probar los daños". Op. cit., p. 410.

La presunción de perjuicio patrimonial en el ámbito de los vicios del consentimiento se asemeja a una del tipo iuris et de iure, puesto que no implica una mera inversión de la carga de la prueba del perjuicio. En esos casos, simplemente, no habrá cabida a la prueba del perjuicio - al no conformar la materia discutida-. GASCón (2010), pp. 131-135. Así, la prueba tendrá por objetivo los hechos constitutivos del vicio del consentimiento que corresponda y el perjuicio patrimonial será una consecuencia jurídica inevitable de la existencia de ese vicio. Consideramos que lo anterior armoniza perfectamente con lo 
contratado bajo esas adversas condiciones- y en la lesión, en cambio, dicho perjuicio deberá ser invocado y acreditado.

En tal sentido, la finalidad que el Código Civil persigue a través de la sanción a los vicios del consentimiento, es prever y anticiparse a un resultado lesivo del negocio celebrado bajo su influjo. Objetivo que es del todo coherente con la finalidad misma del derecho privado, desde su origen romano hasta la actualidad: la protección de los sujetos a través de la tutela del patrimonio ${ }^{52}$.

Por todo lo anterior, consideramos que el argumento de Paola Ziliotto tiene un sentido histórico muy acertado y, en el contexto del Código Civil chileno, puede proyectarse más allá en sus consecuencias. Ese criterio unitario al que se refiere la autora, utilizado para valorar la actividad negocial, otorga en nuestro código, incluso, más preponderancia al contenido contractual que al comportamiento de los contratantes. En consecuencia, el Código Civil chileno va más allá de la mera regulación y sanción de los vicios del consentimiento, velando por el contenido del contrato en varios otros casos en que ha incorporado la rescisión como remedio al desequilibrio contractual ${ }^{53}$.

La paulatina preponderancia histórica adquirida por el dolo, el error y la fuerza -por sobre la lesión-, encontró su génesis en el auge del liberalismo económico, el que supuso que un contrato celebrado de manera libre era, de por sí, justo y equitativo para las partes. En el ámbito jurídico, la preocupación por la voluntad se restringió a la verificación de que

establecido en el art. 11 del C.C., que dice: "Cuando la ley declara nulo algún acto, con el fin expreso o tácito de precaver un fraude, o de proveer a algún objeto de conveniencia pública o privada, no se dejará de aplicar la ley, aunque se pruebe que el acto que ella anula no ha sido fraudulento o contrario al fin de la ley". El nexo que vislumbramos entre la sanción a los vicios del consentimiento - nulidad-y el perjuicio patrimonial, es que no podrá acreditarse que el perjuicio derivado de la lesión no se produjo (gracias a la existencia de una presunción de derecho del perjuicio) y, con ello, evitar la sanción de nulidad del negocio. En la nomenclatura de la norma citada: cuando la ley declara nulo un acto, con el fin de proveer al objeto de conveniencia privada constituido por el consentimiento libre e informado de los contratantes, no se dejará de aplicar la ley, aunque se pretenda acreditar que el acto que ella anula no ha sido contrario al fin de la ley (tutelar la justicia del contenido del contrato).

Ahora bien, es preciso también armonizar esta presunción del perjuicio con la compatibilidad del ejercicio de una acción indemnizatoria basada en la existencia de vicios del consentimiento en el acto o contrato nulo. En tal hipótesis, postulamos que la prueba recaerá, no en la existencia del perjuicio patrimonial -existencia que, como hemos expresado, la ley presume-, sino en la naturaleza y monto de aquel.

${ }^{52}$ Bonfante (1976), tomo IX, p. 173.

${ }^{53}$ Incluso, para algunos autores, nada obsta a que la lesión pueda remediarse fuera de los casos expresamente regulados en el articulado del Código Civil. Entre ellos se encuentra Ducci (2005), pp. 266-267 y LóPEz DíAz (2015), p. 162. 
aquella haya sido manifestada en forma libre, permitiéndose, con ello, que los mecanismos de tutela de la formación del consentimiento adquirieran mayor notoriedad. Esto, en desmedro de la lesión, la que se consideró, desde entonces, un elemento de conflicto que colisionaba con el sagrado principio de la autonomía de la voluntad ${ }^{54}$.

\section{Conclusiones}

A diferencia de los postulados de la doctrina clásica en la materia -que considera como sinónimos a los conceptos de nulidad relativa y rescisióneste trabajo propone un análisis histórico dogmático del título Xx del libro IV del Código Civil, que permite encontrar otro sentido a su denominación: "De la nulidad y la rescisión". Tal análisis nos aclara -al igual que lo hace, desde ya, el mismo enunciado del título $\mathrm{xx}$ - que la nulidad relativa $\mathrm{y}$ la rescisión no son cosas idénticas, sino que, por el contrario, cada una tiene su espacio y su función dentro de la organización interna del Código Civil. En tal sentido, la nulidad relativa opera con la finalidad última de resguardar la buena fe en el comportamiento de los contratantes mediante el control de los denominados vicios del consentimiento. Mientras que, en un sentido más amplio, la rescisión por lesión se orienta a la tutela de la buena fe en el contenido del acuerdo, por cuanto permite demandar judicialmente la ruptura de la convención cuando el desequilibrio contractual traspasa ciertos límites tolerables.

\section{Bibliografía CITADA}

Accatino, Daniela (2015). "La 'teoría clásica' del contrato y la discusión sobre su adaptación judicial”. Revista Chilena de Derecho, vol. 42, n. ${ }^{\circ}$ 1. Santiago.

Alberruche Díaz-Flores, María Mercedes (2010). La rescisión por lesión en el Derecho Civil español. Madrid: La Ley.

Alcalde Silva, Jaime (2010). "La rescisión en el Código Civil chileno", en Estudios de Derecho Civil V, Jornadas Nacionales de Derecho Civil Concepción 2009. Santiago, Abeledo Perrot-Thomson Reuters.

Alessandri Rodríguez, Arturo y Manuel Somarriva Undurraga (1998). Tratado de Derecho Civil, redactado y puesto al día por Antonio Vodanovic H. Santiago:

${ }^{54}$ Pietrobon (1971), p. 51; De la Cámara y Díez-Picazo (1988), p. 52; Medicus (1995), tomo i, p. 39; De Castro y Bravo (2008), vol. iII, p. 15; López Santa María (2010), p. 4; Díez-Picazo y Gullón (2012), vol. il, tomo i, p. 21; Momberg (2013), p. 10; AcCatino (2015), pp. 39-42. 
Editorial Jurídica de Chile (primera edición de la Editorial Jurídica de Chile), tomo II, Partes preliminar y general

Baraona GonzÁlez, Jorge (2011). "Nulidad: ¿ por qué relativa?”, en Juan Andrés VARAs et al. (coord.), Estudios de Derecho Civil, Jornadas Nacionales de Derecho Civil. Santiago: Abeledo Perrot-Thomson Reuters, tomo I.

BELlo, Andrés (1932). Obras completas, edición hecha bajo los auspicios de la Universidad de Chile. Santiago: Editorial Nascimento, tomo v. Proyecto inédito

Bello, Andrés (1981). Obras completas. $2^{\mathrm{a}}$ ed. Caracas: Fundación La Casa de Bello, tomo XV. Código Civil de la República de Chile II

Bonfante, Pietro (1976). Diritto Romano. Opere complete di Pietro Bonfante IX. Milano: Dott. A. Giuffrè, Editore.

Burke, Edmund Plunkett (1830). An historical essay on the laws and the goverment of Rome. Second edition revised. Cambridge: T. Stevenson.

Bueno Delgado, Juan Antonio (2013). "Los rescriptos imperiales como fuente del Derecho". Revista Internacional de Derecho Romano. N. ${ }^{\circ} 11$. Castilla-La Mancha.

Burke, Edmund Plunkett (1830). An historical essay on the laws and the goverment of Rome. Second edition revised. Cambridge: T. Stevenson.

Carrasco Perera, Ángel (2010). Derecho de contratos. Navarra: Aranzadi-Thomson Reuters.

Ciapparoni, Fabrizio (1968). "Voz rescritto. Diritto Romano", in Antonio Azara y Ernesto Eula (dirs.) Novissimo Digesto Italiano. Torino: Vnione TipograficoEdictrice Torinese, vol. XV

Corpus Iuris Civilis cum glossis Accursii (2006). Frankfurt am main: ico Verlag, vol. IV.

Costa Pruneda, David (1890): "De la nulidad y rescisión. Explicación del título xx del libro IV del Código Civil’. Revista Forense Chilena. Tomo vi. Santiago.

De Castro y Bravo, Federico (2008). Derecho Civil de España. Pamplona: Thomson-Civitas, vol. III: El negocio jurídico y la persona jurídica.

De la Cámara Álvarez., Manuel y Luis Díez-Picazo y Ponce de León (1988). Dos estudios sobre el enriquecimiento sin causa. Monografías Civitas. Madrid: Editorial Civitas, S.A.

De la Maza Gazmuri, Iñigo (2011). "La distribución del riesgo y la buena fe. A propósito del error, el dolo y los deberes precontractuales de información”. Revista de Derecho de la Pontificia Universidad Católica de Valparaíso. N. ${ }^{\circ}$ XXXVIII. Valparaíso.

Di PaOla, Santi (1966). Contributi ad una teoria della invalidità e della ineficacia in diritto romano. Milano: Dott. A. Giuffre, Editore.

Delvincourt, Claude Étienne (1813). Cours de Code Napoléon. Paris: P. Gueffier Imprimeur- Librairie. vol. II.

Dítz-PicAzo, Luis (2007). Fundamentos del Derecho Civil patrimonial I. Introducción y teoría del contrato. $6^{\mathrm{a}}$ ed. Pamplona: Thomson-Civitas.

Díez-Picazo, Luis y Antonio Gullón (2012). Sistema de Derecho Civil. 10a ed. Madrid: Tecnos, vol. II, tomo I: El contrato en general. La relación obligatoria. 
Domínguez Águila, Ramón (2008). "Todo el que tenga interés en ello... (sobre el art. 1683 del Código Civil chileno y el interés para alegar la nulidad absoluta", en Fabricio Mantilla y Carlos Pizarro (coords.). Estudios de Derecho Privado en homenaje al profesor Christian Larroumet. Santiago-Bogotá: Fundación Fueyo, Universidad Diego Portales- Universidad del Rosario.

Ducci Claro, Carlos (2005). Derecho Civil. Parte general. Reimpresión de la $4^{\mathrm{a}}$ ed. Santiago: Editorial Jurídica de Chile.

Durantón, Alexandre (1844). Cours de Droit français suivant le Code Civil. $4^{\mathrm{a}}$ ed. Paris: G. Thorel et E. Guilbert, Libraires, tome douzième

FABREs, José Clemente (1908). Obras completas de don José Clemente Fabres, recopiladas y publicadas por la Universidad Católica de Santiago de Chile. Santiago: Imprenta Cervantes, tomo III.

García VAlLÉs, Ricardo (1962). Rescisión por laesio ultradimidium. Barcelona: Bosch, Casa Editorial.

Gascón Abellán, Marina (2010). Los hechos en el derecho. $3^{\text {a }}$ ed. Madrid-BarcelonaBuenos Aires: Marcial Pons.

Gómez VÁsquez, Carlos (2008). "El carácter ‘trágico' de la justicia contractual: a propósito de las relaciones de consumo". Boletín del Ministerio de Justicia. Año 62. $\mathrm{N}^{\mathrm{o}}$ 2061. Madrid.

Guzmán Brito, Alejandro (1996). Derecho Privado Romano. Santiago: Editorial Jurídica de Chile), tomo I.

Heinecio, Juan (1834). Elementos de Derecho Civil, según el orden de las Pandectas. Traducidos y anotados por Miguel de Silva y José Francisco Díaz. Madrid: Imprenta de D. León Amarita, tomo I.

Heinecio, Juan (1835). Recitaciones del Derecho Civil de Juan Heinecio. Traducción al castellano, enriquecida con notas y adiciones considerables, por Don Luis de Collantes y Bustamante. Madrid: Imprenta de P. Sanz, tomo II.

López DíAz, Patricia Verónica (2015). "El principio de equilibrio contractual en el Código Civil chileno y su particular importancia como fundamento de algunas instituciones del moderno Derecho de las obligaciones en la dogmática nacional". Revista Chilena de Derecho Privado. N. ${ }^{\circ}$ 25. Santiago.

López Santa María, Jorge (2010). Los contratos, Parte General. $5^{\mathrm{a}}$ ed. Santiago: Legalpublishing-Thomson Reuters.

Manresa y Navarro, José María (1907). Comentarios al Código Civil español. $2^{\mathrm{a}}$ ed. corregida y aumentada. Madrid: Imprenta de la Revista de Legislación, tomo VIII.

Martín Pérez, José Antonio (1995). La rescisión del contrato. En torno a la lesión contractual y el fraude a los acreedores. Barcelona: José María Bosch Editor.

Masi, Antonio (1978). Voz "Nullità (storia)", en Enciclopedia del Diritto. Milán: Giuffrè Editore, tomo XXVIII.

Medicus, Dieter (1995). Tratado de las relaciones obligacionales. (trad.) Ángel Martínez Sarrión. Barcelona: Casa Editorial, S.A., vol. I. 
Merello, Ítalo (1989). "La lesión en la venta de oficios en Indias". Revista Chilena de Historia del Derecho. N. ${ }^{\circ} 15$. Santiago.

Merino, José María (1908): Nulidad y rescisión. Memoria de prueba para optar al grado de licenciado en la Facultad de Leyes y Ciencias Políticas de la Universidad de Chile. Santiago: Facultad de Leyes y Ciencias Políticas de la Universidad de Chile.

Momberg Uribe, Rodrigo (2013). "El control de las cláusulas abusivas como instrumento de intervención judicial en el contrato". Revista de Derecho. Vol. XXVI, n. ${ }^{\circ}$ 1. Valdivia.

Morales Moreno, Antonio-Manuel (2011). “¿Es posible construir un sistema precontractual de remedios? Reflexiones sobre la Propuesta de modernización del Derecho de obligaciones y contratos en el marco del Derecho europeo", en Klaus Albiez Dohrmann (dir.). Derecho Privado Europeo y modernización del Derecho contractual en España. Barcelona: Atelier Libros Jurídicos, parte III, capítulo IV.

Piccirillo, Alessandro (1968). "Voz rescissione. Diritto Romano", in Ernesto Eula (dirs.) Novissimo Digesto Italiano. Torino: Vnione Tipografico-Edictrice Torinese, vol. XV

Pietrobon, Vittorino (1971). El error en la doctrina del negocio jurídico. Traducción y concordancias al Derecho español por Mariano Alonso Pérez. Madrid: Editorial Revista de Derecho Privado.

Pothier, Robert Joseph (1821). Oeuvres complètes. Traité des obligations, nouvelle. Edition ornée du portrait de l'auteur, publiée par M. Siffrein. Paris: Chez L'Éditeur, tome premier.

Rossel Saavedra, Enrique (1926). Teoría de las nulidades. Memoria de Prueba para optar al grado de licenciado en la Facultad de Leyes y Ciencias Políticas. Santiago: Imprenta y Litografía "Balcells \& Co.".

S., O. (1885). "De la nulidad de los actos y contratos". Revista Forense Chilena. Tomo I. Santiago.

Sciuto, Patricia (2000). "Sulla c.d. rescissione per lesione enorme". Labeo. Vol. 46, n. $^{\circ}$ 3. Napoli.

Touluier, Charles B. M. (1824). Le Droit Civil français, suivant l'ordre du code, ouvrage dans lequel on a taché de réunir la théorie a la pratique. Paris, Chez Warée, oncle, Librairie de la Cour Royale, tome viI.

Vera, Robustiano (1896). Código Civil de la República de Chile comentado y explicado por Robustiano Vera. Santiago: Imprenta de "El correo", tomo v.

VIAL DEL Río, Víctor (2015). Teoría general del acto jurídico. $5^{\mathrm{a}}$ ed. actualizada y aumentada. Santiago: Editorial Jurídica de Chile.

Walker Silva, Nathalie (2017). "Las leyes De rescindenda venditione y la configuración originaria de la rescisión del contrato por lesión enorme". Ars Boni et Aequi. Vol. 13, n. ${ }^{\circ}$ 2. Santiago.

Walker Silva, Nathalie (2017a). "Bases para una deconstrucción del concepto de rescisión por lesión”. Revista Chilena de Derecho. Vol. 44, n. ${ }^{\circ}$ 3. Santiago. 
Walker Silva, Nathalie (2019). La rescisión por lesión en el Código Civil chileno. Historia, regulación y vínculos con las nulidades. Valencia: Tirant lo Blanch.

Ziliotto, Paola (2007). "La misura della sinallagmaticità: buona fede e 'laesio enormis", en Luigi GaROfalo (ed.). La compravendita e l'interdipendenza delle obligationi nel Diritto Romano. Padova: Cedam, tomo primo. 